\title{
Testimonios en Democracia: EL JUICIO a las Juntas Militares en Argentina
}

Testimonies in Democracy: the Trial of the Military Juntas in Argentina

\section{Claudia Bacci \\ Universidad de Buenos Aires (Argentina)}

RESUMEN: Los testimonios sobre la represión en la última dictadura en Argentina (1976-1983) fueron esenciales para la denuncia pública en diferentes foros. El Juicio a las Juntas Militares en 1985 fue un punto de inflexión en la legitimación de los testigos en el espacio público, en un contexto social ambiguo frente al relato de las víctimas. Uno de sus efectos centrales fue reinscribir en términos colectivos e institucionales lo que sólo aparecía como meramente personal.

En este trabajo se presenta un análisis de las tensiones y debates en torno al Juicio, las expectativas de los testigos y sus evaluaciones actuales, 30 años después de su realización. Examino una selección de fragmentos significativos extraídos de un corpus de 37 testimonios orales de testigos del Juicio, teniendo en cuenta las líneas de tensión discursivas y el desplazamiento temporal en los testimonios con el fin de reconocer las transformaciones y resignificaciones subjetivas desplegadas en estos ejercicios de memoria.

Palabras claVe: testimonio, subjetividad, justicia transicional, memoria.

RESUM: Els testimonis sobre la repressió en l'última dictadura a l'Argentina (1976-83) foren essencials per a la denúncia pública en diversos fòrums. El judici a les juntes militars, en 1985, va ser un punt d'inflexió en la legitimació dels testimonis en l'espai públic, en un context social ambigu enfront del relat de les víctimes. Un dels efectes centrals fou reescriure en termes col-lectius i institucionals els que només apareixia com a merament personal. 
Aquest treball presenta una anàlisi de les tensions i dels debats al voltant del judici, les expectatives dels testimonis i les seues avaluacions actuals, trenta anys després d'haver-se realitzat. Examinem una selecció de fragments significatius, trets d'un corpus de trenta-set testimonis orals del judici, tenint en compte les línies de tensió discursives i el desplaçament temporal en els testimonis, a fi de reconèixer les transformacions i resignificacions subjectives desplegades en aquests exercicis de memòria.

Paraules clau: testimoni, subjectivitat, justícia transicional, memòria.

ABSTRACT: Testimonies on the repression during the last dictatorship in Argentina (1976-1983) were essential for public denunciation in different forums. The Trial of the Military Juntas in 1985 marked a turning point in legitimizing the witnesses in public spaces, in the ambiguous social context the victims' accounts faced. One of its central effects was to restore in collective and institutional terms what had appeared before as merely personal.

This paper presents an analysis of the tensions and debates around the Trial, the witnesses' expectations and their current evaluations 30 years after its completion. I examine a selection of significant fragments taken from a corpus of 37 oral testimonies from the Trial witnesses, considering the lines of discursive tension and temporal displacement in the testimonies in order to recognize the transformations and subjective resignifications deployed in these memory exercises.

KeYWORDs: testimony, subjectivity, transitional justice, memory. 
The reward of storytelling is to be able to let go.

Hannah Arendt (1983 [1968])

\section{El Juicio a las Juntas Militares: una introducción}

E

10 de diciembre de 1983, luego de siete años de dictadura en Argen-

tina, se inició un periodo de recuperación democrática vacilante. Apenas asumido, el Congreso y el Poder Ejecutivo dictaron tres instrumentos legales que dieron forma al tratamiento de las violaciones a los derechos humanos cometidas por el terrorismo de Estado: ${ }^{1}$ la anulación de las leyes de impunidad y auto-amnistía del «Proceso de Reorganización Nacional»; los Decretos 157 y 158 ordenando el procesamiento de los dirigentes de las organizaciones guerrilleras y de las tres Juntas Militares de la dictadura, respectivamente; y la creación en 1984 de la Comisión Nacional de Desaparición de Personas (CONADEP) que investigó y reunió pruebas de las violaciones a los derechos humanos (Nino, 1997; Crenzel, 2008). Esas iniciativas concluyeron en 1985 con el enjuiciamiento de los responsables de las tres Juntas Militares, conocido como Juicio a las Juntas Militares. ${ }^{2}$

1. El terrorismo de Estado se fundó en la planificación sistemática de la violación de derechos humanos fundamentales por el Estado, articulando estrategias, actores y acciones de instituciones represivas legales con actores y circuitos paralegales. Operaba a través del secreto y la negación de las órdenes y acciones de los diversos actores de las fuerzas represivas estatales (Mignone y Conte, 2006 [1981]).

2. El juicio oral y público (Causa $\mathrm{N}^{\circ} 13 / 84$ ) estuvo a cargo del Juzgado $\mathrm{N}^{\circ} 1$ de la Cámara Federal de Buenos Aires, integrado por los jueces Jorge E. Torlasco, Ricardo Gil Lavedra, Carlos L. Arslanian, Jorge Valerga Aráoz, Guillermo Ledesma y Andrés D’Alessio. El equipo de la Fiscalía, a cargo de Julio C. Strassera y Luis Moreno Ocampo, construyó los «casos testigos» por los cuales se imputó a los nueve comandantes de las tres Juntas Militares según el Código Penal vigente en ese momento (homicidio, privación ilegítima de la libertad seguida de homicidio, privación ilegítima de la libertad simple, tormentos, violaciones y robo). El Juicio transcurrió entre el 22 de abril de 1985 y el 9 de diciembre de 1985, y condenó a Jorge Videla y Emilio Massera (prisión perpetua), Roberto Viola (17 años), Armando Lambruschini (8 años), Orlando Agosti (4 años y 6 meses en suspenso). Fueron absueltos de todos los cargos Omar Graffigna (integrante de la segunda Junta) y los integrantes de la tercera Junta - Leopoldo Galtieri, Jorge Anaya y Basilio Lami Dozo - C Cfr: http://www.derechos.org/nizkor/arg/ causa13/fallo.html. 
Este juicio constituyó un punto de inflexión en diversos sentidos. En primer lugar, a diferencia de lo ocurrido hasta ese momento en el resto de los países del Cono Sur que habían pasado por regímenes dictatoriales, el Juicio a las Juntas representó un corte político histórico que reconocía una serie de iniciativas novedosas por parte de las organizaciones sociales dedicadas a la lucha por los derechos humanos (Sikkink, 2008). En segundo lugar, a diferencia de la CONADEP y lo que después se conocerían como «comisiones por la verdad», su objetivo central era esclarecer y determinar las responsabilidades penales de los integrantes de las Juntas a través de instrumentos jurídicos del Código Penal, en una articulación novedosa $-\mathrm{y}$ arriesgada - con el Código Militar vigente hasta entonces. ${ }^{3}$ Finalmente, el Juicio se convirtió en un escenario inesperado de legitimación pública de los testigos, en un contexto social todavía ambiguo ante la representación pública del sufrimiento colectivo, con consecuencias políticas que se extienden al presente. Así, uno de sus efectos más importantes fue reinscribir la verdad de lo ocurrido en términos colectivos e institucionales (González Bombal, 1995; Wiewiorka, 1998; Felman, 2002; Arendt, 2002 [1963]; Peris Blanes, 2005).

En el presente trabajo analizo las tensiones y debates en torno al Juicio, las expectativas y balances de quienes testimoniaron en él, a 30 años de su realización. ${ }^{4}$ En el apartado 2 planteo cómo el Juicio a las Juntas constituyó un espacio y un momento ineludible de ampliación de los límites de lo enunciable en relación con los efectos sociales y subjetivos del terrorismo de Estado en Argentina. En los apartados 3 al 5 despliego el análisis de algunos fragmentos seleccionados del corpus de 37 testimonios audiovisuales consultados en el Archivo Oral de Memoria Abierta, donde fueron producidos desde

3. El gobierno intentó que las propias FFAA aplicaran sanciones a los responsables, pero ante el fracaso de esta estrategia la Justicia ordinaria dio cumplimiento al Decreto 158/83. Siguiendo especificaciones del Código Militar se realizó un juicio oral y público, instancia inexistente entonces en la justicia ordinaria (Nino, íd.).

4. Este trabajo forma parte de la tesis en curso en el Doctorado en Ciencias Sociales (UBA), sobre las transformaciones subjetivas en tres escenas testimoniales diversas en su configuración e historicidad — el Juicio a las Juntas Militares, el Juicio por la Verdad de La Plata (1998-2008) y el Archivo Oral de Memoria Abierta-. Agradezco las sugerencias realizadas por las/los evaluadores de la revista, que me permitieron repensar algunas cuestiones de este trabajo. 
2001 hasta el presente..$^{5}$ El corpus seleccionado incluye tanto a sobrevivientes como a testigos familiares que fueron presentados por la Fiscalía en el Juicio, y que desde 2001 han brindado sus testimonios al Archivo Oral mencionado. De este modo, los testimonios recorren un arco temporal complejo y rico en relación a sus contextos de enunciación: desde un escenario de impunidad judicial hasta el periodo de reapertura de los procesos por delitos de lesa humanidad de la dictadura iniciado en 2006 y que continúa hasta el presente. ${ }^{6}$ Planteo la potencialidad de la práctica testimonial para comprender los desplazamientos subjetivos en el propio proceso narrativo, aun en contextos altamente formalizados como un juicio oral penal. Abordo también las expectativas, tensiones y temores ante el Juicio y sus resultados, así como la propia experiencia de testimoniar en ese marco, desde el presente, atendiendo a las resignificaciones y temporalidades mixtas desplegadas en estos ejercicios de memoria. Las consideraciones finales recuperan reflexivamente los puntos centrales del trabajo y plantean algunas líneas posibles de trabajo a desarrollar.

\section{Paradojas de la escena jurídica como paradigma normativo del testimonio}

Desde el retorno de la democracia en 1983 se ha insistido en la necesidad de multiplicar la reflexión acerca del periodo del terrorismo de Estado en Argentina y su ominosa figura de la desaparición. Como afirma Roberto Pittaluga (2006: 40), es de vital importancia «la producción testimonial, de la

5. El Archivo Oral produce testimonios audiovisuales de acceso público sobre el terrorismo de Estado, la vida social y política en los años 60-70 y la búsqueda de verdad y justicia de los organismos de derechos humanos y la sociedad civil argentinas. URL: http://www.memoriaabierta.org.ar/bases/opac/Registros/oral/index.html.

6. Considero que la amplitud temporal y la heterogeneidad de formas testimoniales de los testimonios del Archivo constituyen elementos de una riqueza insoslayable que, al contrario de ciertas vinculaciones fetichistas con la producción de materiales para el análisis en las ciencias sociales, merece escuchas atentas a los desplazamientos temporales y contextuales que cada voz introduce en él a la vez que habilita una problematización de las puestas en serie discursivas. Estas operaciones analíticas permiten un trabajo de historización que desnaturaliza la idea de «evidencia de la experiencia» (Scott, 2001). Sobre la relación entre testimonio y documento en la historia, y sobre la construcción del corpus, ver: Ricoeur (2004); Aguilar et al. (2014). 
palabra de los testigos - incluso de aquellos que no saben que lo han sido-, pues también sobre esas superficies textuales debemos pensar, interpretar»». ${ }^{7}$

Institucionalización de la democracia, rechazo de las formas de violencia política y estatal precedentes, e instauración de la perspectiva de los derechos humanos como fundamento democrático fueron los tres ejes que concentraron las expectativas de la «transición democrática», condensadas en el Juicio de manera especial. La fotografía de los ex comandantes de las tres Juntas Militares de pie frente al Tribunal constituye desde entonces una imagen-emblema de esa frontera entre dictadura y democracia que, en otros aspectos, aún permanecía difusa (Acuña y Smulovitz, 1995; Nino, ob. cit.; Feld, 2002). En esa imagen se cifró la institución de los derechos humanos como instancia de legitimación y reconocimiento de las denuncias realizadas por organismos de derechos humanos y sobrevivientes de los centros clandestinos de detención desde fines de $\operatorname{los} 70 .^{8}$

El tribunal que tomó a su cargo el Juicio estableció el procedimiento del mismo a través de la Acordada $\mathrm{N}^{\circ} 14$ (27/03/1985) que resolvía su filmación completa para garantizar su desarrollo e imparcialidad y preservar un documento de ese acontecimiento que vislumbraba como histórico. ${ }^{9}$ En su análisis acerca de la producción y circulación de esas imágenes, Claudia Feld (ob. cit.) señala la coincidencia entre el Gobierno y la Cámara Federal en torno a evitar que se convirtiera en un circo que irritara a las Fuerzas Armadas. Las audiencias, con la presentación de unos 2000 testimonios de la fiscalía y las defensas, transcurrieron entre el 22 de abril y el 14 de agosto en la Sala de Acuerdos de la Corte Suprema de Justicia en la ciudad de Buenos Aires. En septiembre se presentó la acusación, entre octubre y noviembre las defensas hicieron sus alegatos, y el 9 de diciembre de 1985 el tribunal dictó su sentencia fundada sobre 709 casos probados durante las audiencias. ${ }^{10}$

7. $\quad C f r$. Calveiro (2008) y Oberti (2009).

8. Sobre las denuncias realizadas desde fines de los 70, ver: CADHU, 1979; CIDH, 1980; Jelin, 1995; Crenzel, 2007.

9. Fue filmado en video por el canal estatal colocado bajo resguardo de la Cámara Federal. En 1988, tras dos levantamientos militares, los ex jueces enviaron una copia en custodia al Parlamento Noruego.

10. Ibíd. Nota 2. 
A diferencia de otras transiciones políticas en el Cono Sur de América Latina, el Juicio de 1985 ofrecía un escenario público donde establecer la verdad de los hechos ocurridos e identificar a sus responsables (Funes, 2009). Para numerosos espectadores, el Juicio escenificó una experiencia política transformadora radical y permanente (Nino, ob. cit.; Vezzetti, 2002), lo cual minimizaba la distancia entre una lógica política y otra jurídica, ${ }^{11}$ a la vez que desconocía el cierre institucional que supusieron las «leyes de impunidad» frente al reclamo político del movimiento de derechos humanos por Juicio y castigo a todos los culpables (Memoria Abierta, 2010). ${ }^{12}$ En la perspectiva de los organismos de derechos humanos — en especial, Madres de Plaza de Mayo y la Asociación de Familiares de Detenidos y Desaparecidos por Razones Políticas_-, este juicio establecía un piso de Justicia que había que continuar y profundizar en otras direcciones, que derivaría más tarde en la consigna Memoria, Verdad y Justicia (Jelin, 1995).

Pese al interés social que generó el Juicio y a la decisión del tribunal de filmar las audiencias, las restricciones a su difusión televisiva limitaron su potencial alcance público. ${ }^{13}$ No obstante esto, se visibilizó por primera

11. Carlos Acuña y Catalina Smulovitz (ob. cit.) diferencian la lógica política de la jurídi$c a$. Si la primera articula intereses particulares o sectoriales y supone una intervención o acción (directamente o a través de representantes), la segunda supone el criterio «neutral» de los jueces según reglas preestablecidas en base a principios generales legitimados institucionalmente, donde intervienen en roles subordinados las víctimas como testigos y los victimarios como acusados, mientras que «las partes con intereses estrictamente políticos [devienen] “observadores” de la acción» fuertemente controlados. Por otra parte, la «economía del tribunal» (Assmann, 2006) trata la información testimonial a título individual como prueba, restringiendo los datos y relatos a ser incluidos en el proceso. Cfr. E. Kaufman (1991).

12. Las Leyes de Punto Final (1986) y de Obediencia Debida (1987), junto a los indultos presidenciales de 1989 y 1990, cerraron las causas contra el terrorismo de Estado. En 2003 el Congreso argentino declaró la nulidad legislativa de ambas «leyes de impunidad», y la imprescriptibilidad de los crímenes de lesa humanidad según convenciones internacionales. En 2005 la Corte Suprema declaró inconstitucionales esas leyes y en 2006 la Cámara de Casación Penal anuló los indultos concedidos en los 90. Estas medidas reabrieron los juicios truncos desde 1987 y permitieron el inicio de nuevas causas que continúan hasta hoy.

13. Ver: Feld, ob. cit.: 17-37. El único requisito para presenciar las audiencias era el registro previo de los asistentes. El Tribunal entregaba sólo 3 minutos de imágenes editadas sin sonido para su difusión diferida. No se permitía entrar con cámaras o grabadores. Las transcripciones de testimonios, alegatos y la sentencia final, se publicaron en el Diario del Juicio (27/05/1985 a 28/01/1986). El registro audiovisual completo es de acceso público en Memoria Abierta (Argentina) y en la Universidad de Salamanca (España). URL: http://www.memoriaabierta.org.ar/juicioalasjuntas/ y http://gredos. usal.es/jspui/handle/10366/120417. 
vez el carácter del terrorismo estatal, ampliando los límites de lo enunciable (Pollack 1986), se hizo lugar a la escucha del sufrimiento y al derecho de las víctimas a reclamar justicia públicamente (Segato, 2010), a la vez que constituyó un espacio de impugnación política a la dictadura a través de la palabra de los propios testigos. Por otra parte, la legitimidad alcanzada por éstos a partir de allí, sumada a la preeminencia del paradigma jurídico de los derechos humanos en el tratamiento del pasado reciente, delimitaron otras formas y espacios de enunciación sobre el pasado —en particular los referidos a la militancia política de quienes habían sido secuestrados y desaparecidos-, encapsulando la escucha social de las experiencias en la lucha armada (da Silva Catela, 2004; Jelin, 2007 y 2012). Esto último excedía por cierto las intenciones fundacionales de los actores políticos o la perspectiva institucional judicial, ligándose al escenario político-jurídico de los primeros años de democracia. ${ }^{14}$ Apenas un año después del Juicio, los sucesivos levantamientos militares (1987, 1988 y 1990) abrieron un periodo de casi diez años de impunidad en el país para los crímenes del terrorismo de Estado. Este nuevo escenario dio lugar, sin embargo, a la emergencia de otros espacios de enunciación para los testigos (Memoria Abierta, 2010). Pasaría todavía algún tiempo para que formas diversas del testimonio sobre la militancia fueran públicamente admitidas y escuchadas (Oberti, 2014).

\section{Nombrar el sufrimiento y resistir en el testimonio}

Como parte de dinámicas sociales y políticas específicas, los procesos de construcción de memorias sobre el pasado reciente en Argentina — de los cuales los testimonios son apenas un factor - continúan abiertos. Inarchivables, como afirmaba Agamben (2002) sobre los testimonios del exterminio judío bajo el nazismo, los testimonios del terrorismo de Estado insisten en ser escuchados en cada fecha-monumento, cada nueva instancia judicial, cada espacio de memoria, pero a la vez lo hacen desde la voz descentrada del sujeto (Dollar, 2007:

14. El Decreto 157/83 tuvo vigencia hasta los indultos de los años 90; sumado a la estigmatización social, constituyó un límite a los relatos sobre la militancia revolucionaria y las acciones armadas de los 70 . 
116-118), que anuda lo social y lo más individual, sin poder evitar las lagunas y los olvidos, trayendo siempre a cuestas su anacronismo desbordante y productivo. Los testimonios se despliegan al tiempo que la narración excede la continuidad cronológica y se entrelaza con esa «zona de asociaciones» (Richard, 2010: 16) que constituye la memoria, que van «de la repetición fija del pasado literal que retiene la cita en bruto hacia la dinámica recreativa de un pasado-presente hecha de identificación pero también de separación y distanciación entre lo mismo y lo otro» (Íd.: 267, su énfasis). En contra de las «retóricas domesticadoras», insiste Richard, de las «tecnologías del olvido» y las «gestualidades refractarias» al recuerdo, la cualidad propia del testimonio de hacer del pasado una «fuerza crítica de extrañamiento» en el presente se acentúa en el proceso social de su constitución como «archivo» (Íd.: 16-17). Según Aleida Assmann (2006), el testimonio es el punto de sutura efímero entre lo que en un sujeto hay de sufrimiento y padecimiento del trauma, su afección como víctima, y su agencia —e incluso su posibilidad de resistencia — como testigo. Dori Laub (1995) reafirma esto a partir de su experiencia como sobreviviente del exterminio judío durante la Segunda Guerra Mundial, y como entrevistador del Archivo Audiovisual Fortunoff de Testimonios sobre el Holocausto en la Universidad de Yale, «The testimony is, therefore, the process by which the narrator (the survivor) reclaims his position as a witness: reconstitutes the internal 'thou,' and thus the possibility of a witness or a listener inside himself. [...] In my experience, repossessing one's life story through giving testimony is itself a form of action» (ob. cit., 70).

El entramado de historia, narración y memoria que tiene lugar en todo acto de testimoniar, se articula en el compromiso intersubjetivo entre el narrador y su escucha, donde el testimonio como «dispositivo de escucha» habilita la emergencia del sufrimiento subjetivo en el relato de los hechos (Roy, 2013). Este dispositivo exige atención no sólo al contenido, su referencialidad, sino también a la voz y expresión de quien testimonia, una atención cuidadosa y responsable a los vacíos de sentido, a sus silencios y dudas, a lo que nombran y a lo que balbucean de manera paradojal (Bacci, Oberti y Skura, 2012).

La puesta en escena institucional del Juicio a las Juntas reconstruía en el espacio la estructura jerárquica del tribunal. Por un lado, el propio edificio del Palacio de Justicia no estaba preparado para el tipo de audiencia que se 
desarrollaría allí. El lugar destinado a los testigos, de frente al tribunal y de espaldas el público en la sala, fijaba la relación entre los actores, suponía el orden de preguntas y respuestas, e impedía el diálogo directo con la fiscalía y los defensores, a la vez que obturaba el ángulo de las cámaras que sólo podían filmar a los testigos de perfil o de espaldas (Kaufman, 1991). Ángel Ruani, ${ }^{15}$ sobreviviente y testigo clave por la desaparición de otro detenido en el centro clandestino de detención (CCD) del Servicio de Informaciones de Rosario, se refiere así a su entrada en la Sala:

No es fácil estar delante de un tribunal oral contando las cosas... No por la cuestión de lo que nos puede doler de las cosas que nos pasaron... Yo recuerdo que cuando entré a la Cámara Federal de Buenos Aires, en la Causa 13, en el Juicio a los Comandantes, no fue fácil sentarse frente al Tribunal, arriba frente a la Cámara, Ledesma, Arslanián—, mirando una araña [artefacto de iluminación] que tenía arriba, que nunca había visto una araña así yo, y empezar a contar parte de este relato, quizás no tanto, pero parte de este relato muy específico que hace a las torturas y a todo lo que hemos sufrido, ¿no? No es fácil. [Mi énfasis.]

Ruani todavía recuerda la impresión de esa lámpara, el peso simbólico del lugar. La transición temporal recurrente que marca su narración - «No es fácil estar delante de un tribunal oral», «no fue fácil». «No es fácil»—, anuda y alterna el pasado del Juicio y el presente del Archivo, estableciendo a la vez diferencias entre relatos — «contar parte de este relato, quizás no tanto, pero parte...»- y refiriendo «quizás» a los distintos escenarios y circunstancias en que testimonió. También da cuenta de los desplazamientos espaciales y subjetivos complejos que escenifica en la referencia a la ubicación de los testigos «frente al tribunal» y a su vez debajo — «arriba — frente a la Cámara...»-, no sólo debido al desnivel entre el estrado de los Jueces y el resto de la sala, sino porque «estar de frente al tribunal» significa también someterse a él, exponerse al escrutinio de la Justicia y recordar allí «todo lo que hemos sufrido». Por otro lado, el infinitivo «estar delante de un tribunal» y el pasaje, primero hacia la primera persona del plural que asume la dificul-

15. Memoria Abierta, Testimonio de Ángel Ruani, Rosario, 2010. Militante político y barrial, fue secuestrado el 21 de agosto de 1976 por el Servicio de Informaciones de la Unidad Regional II de la Jefatura de Policía de Rosario. Permaneció detenido en diferentes cárceles hasta el 3 de diciembre de 1983. 
tad de la narración y la colectiviza, y luego a la primera persona singular que evoca la impresión de la verticalidad y del tamaño de los objetos en relación al propio cuerpo, resalta el lapso en que las «cosas que pasaron» y lo ya sufrido pueden aún doler en tiempo presente. El testimonio de Ruani, tomado en 2010 en un marco de procesos en curso en los cuales continúa testimoniando, recupera esa instancia de actualización que todo testimonio contiene, y abre espacio a una reflexión acerca del propio trabajo de rememorar (Bacci, Oberti y Skura, ob. cit.).

No obstante esa potencial apertura social a la escucha que habilita un testimonio, su supuesta capacidad reparadora exige ser puesta en cuestión (Laub, ob. cit.; Jelin, 2006; Kaufman, 2014), puesto que nada asegura que quienes testimonian aún en sede judicial — donde se reconocen como sujetos de derecho-, sean reconocidos también como sujetos que sufren en el propio acto de narrar su experiencia. Pese a esto, sostengo que el testimonio excede siempre su encuadramiento en el marco jurídico (o en el lugar pasivo de la respuesta a unas preguntas). En ocasiones, el testimonio logra resistir las limitaciones de la constitución de la prueba y de la provisión de información (Richard, ob. cit.; Messina, 2012). Esta cualidad resistente del testimonio ante lo procedimental es una de las dimensiones que se aprecian en los testimonios del Archivo Oral sobre el Juicio a las Juntas.

\section{El fin de la justicia}

Desde su apertura el 22 de abril de 1985 y hasta fines de agosto de ese año, la Sala de Audiencias dispuso lugares reservados para invitados especiales, prensa nacional e internacional y público general, manteniéndose ocupada a pleno a lo largo de todo el proceso. Jorge Luis Borges asistió como invitado el lunes 22 de julio. Uno de los testigos ese día fue Víctor Basterra, sobreviviente del centro clandestino de detención de la Escuela de Mecánica de la Armada (ESMA). ${ }^{16}$ Borges escribió días después una Carta de Lector publicada

16. La ESMA funcionó como CCD entre marzo de 1976 y noviembre de 1983, con alrededor de 5000 detenidos de los cuales sólo sobrevivieron unos 200 (CONADEP, 1985). 
en diversos medios gráficos, con una breve crónica donde reflexionaba sobre lo que esperaba y lo que resultó de ese día:

He asistido, por primera y última vez, a un juicio oral. Un juicio oral a un hombre que había sufrido unos cuatro años de prisión, de azotes, de vejámenes y de cotidiana tortura. Yo esperaba oír quejas, denuestos y la indignación de la carne humana interminablemente sometida a ese milagro atroz que es el dolor físico. Ocurrió algo distinto. [...] De las muchas cosas que oí esa tarde y que espero olvidar, referiré la que más me marcó, para librarme de ella. Ocurrió un 24 de diciembre. Llevaron a todos los presos a una sala donde no habían estado nunca. No sin algún asombro vieron una larga mesa tendida. Vieron manteles, platos de porcelana, cubiertos y botellas de vino. Después llegaron los manjares (repito las palabras del huésped). Era la cena de Nochebuena. Habían sido torturados y no ignoraban que los torturarían al día siguiente. Apareció el Señor de ese infierno y les deseó Feliz Navidad. No era una burla, no era una manifestación de sí mismo, no era un remordimiento. Era, como ya dije, una suerte de inocencia del mal. (El País, 10/08/1985) [Mi énfasis.]

Borges, el lector-espectador, expresa su turbación ante este testimonio, que espera olvidar, dejando atrás la carga de experiencia del testimonio de la que quiere librarse, narrándola. El testimonio de Basterra incluyó la presentación de documentos que probaban la existencia del CCD de la ESMA, menciones a los detenidos desaparecidos que pudo ver allí, su propia travesía, e identificó a sus perpetradores (Feld, 2014). Borges sólo tuvo que escuchar ese testimonio para comprender que lo que había ocurrido durante la dictadura desafiaba toda comprensión, aunque a la vez reconocía en ese testimonio «algo distinto» que el horror.

El derrotero testimonial de Basterra, iniciado apenas liberado en 1984, continúa hasta el presente ante distintas instancias públicas, tanto en juicios como en los medios. En su testimonio para el Archivo Oral de Memoria Abierta, ${ }^{17}$ cuando apenas habían reinicado las causas tras el fin de la impunidad judicial, narró el trascurso personal de su testimonio y evocó las dudas y

17. Memoria Abierta, Testimonio de Víctor Melchor Basterra, Buenos Aires, 2008. Militante gremial y político en los 70, fue secuestrado el 10 de agosto de 1979 y permaneció en cautiverio en la ESMA hasta fines de 1983. 
desconfianzas ante el Juicio. Estas dudas se referían, en particular, a la limitación de las acusaciones a las cúpulas de las tres Juntas, que excluiría la cadena de subordinados responsables en la represión. Basterra insiste en la importancia de testimoniar «porque trasciende todo», pero dice también que dar ese paso ante la Justicia — que durante la dictadura había funcionado como un accesorio del terrorismo de Estado - generaba suficientes temores y desconfianzas como para que los testigos mantuvieran su «distancia» respecto a las acciones del tribunal. Basterra aportó en ese contexto tan complejo una cantidad de documentos que se han mostrado de una gran fecundidad tanto para las condenas del Juicio como para las causas actuales. Sin embargo, la desconfianza no era vana, ya que una parte de ese material se perdió en los recovecos judiciales posteriores (Feld, 2014). No obstante la disconformidad por sus limitaciones, los testigos pronto advirtieron la posibilidad de que su difusión y alcance públicos permitieran que la verdad fuera reconocida socialmente y que la memoria reemplazara el prejuicio y el desconocimiento hacia el sufrimiento de los testigos. Este reconocimiento y legitimación son «algo distinto» de la justicia y la verdad reclamadas, configurando más bien ejercicios de memoria que los testigos reiteran cada vez en diferentes escenarios, con grandes costos y sin garantías. ${ }^{18}$

Varios testigos, en particular quienes habían interpelado a la Justicia como familiares buscando saber acerca de sus seres queridos secuestrados y desaparecidos, relatan haber testimoniado con total desconfianza hacia el proceso de justicia en su conjunto. Ni su publicidad, ni sus resultados les parecían ni entonces ni después - suficientes frente a las limitaciones y dilaciones de la Justicia. María del Rosario Cerruti ${ }^{19}$ declaró como testigo por el secuestro de un grupo de familiares y activistas de derechos humanos en la Iglesia de

18. La amenaza hacia los testigos continúa vigente, como demuestra el secuestro y desaparición de Julio López luego de testificar contra el ex comisario Miguel Etchecolatz en 2006. Hasta hoy se desconoce su destino. López había sido secuestrado y estuvo en cautiverio en diferentes CCD de Buenos Aires entre el 21 de octubre de 1976 y el 25 de junio de 1979. Otros testigos de causas abiertas desde 2006 han denunciado amenazas y secuestros intimidatorios.

19. Memoria Abierta, Testimonio de María del Rosario Cerruti, Buenos Aires, 2006. Madre de Fernando Cerruti, secuestrado el 10 de mayo de 1976, quien continúa desaparecido desde entonces. Cerruti fue una de las fundadoras de la Asociación Madres de Plaza de Mayo, que integró hasta 1993. 
la Santa Cruz. ${ }^{20} \mathrm{Al}$ preguntársele en 2006 por sus expectativas ante el Juicio, recuerda una dura conversación con el entonces Presidente Raúl Alfonsín en la que éste reconocía las limitaciones que tendría ese proceso. No obstante eso, Cerruti asistió como testigo, y destaca la diferencia entre el procedimiento judicial y la Justicia buscada:

Yo fui a declarar porque me citó el juez, lógico, no me iba a negar. Me citaron porque era testigo del secuestro de dos madres y de la monja, pero fui a declarar porque me citó el juez y listo, pero yo no creí en el Juicio. Todos dicen: «Y bueno, en ninguna parte... ni en Chile, ni en Uruguay, en ningún lado hubo un Juicio...». Está bien, pero no sirvió para nada. Para el fin de la Justicia que se buscaba no sirvió.

Cerruti no acepta atenuantes en la búsqueda de justicia y de verdad, ni encuentra que la potencial reparación, que podría traer a sobrevivientes y familiares, justifiquen su confianza en los resultados o efectos del Juicio. El «fin de la Justicia», en el sentido de objetivo de que se supiera la verdad y que se castigara a todos los culpables, constituyó uno de los ejes de reclamo del movimiento de derechos humanos hacia los gobiernos democráticos desde 1983. Como afirma Laub (ob. cit.) estos crímenes desafían los alcances del pensamiento, la memoria y el discurso. En este sentido, la institución jurídica resulta insuficiente para dar lugar al pasaje desde el silencio y el ocultamiento a la memoria y la escucha sociales.

Otros testigos señalaron la importancia de reconstruir la confianza perdida en la Justicia incluso en tiempos tan laxos y con los obstáculos de una democracia muy condicionada. Enrique Fukman ${ }^{21}$ recuerda su participación en el

20. Entre el 8 y el 10 de diciembre de 1977 fueron secuestrados de la Iglesia de la Santa Cruz 12 activistas del movimiento de derechos humanos y familiares de desaparecidos: Ángela Auad, Raquel Bulit y su marido Gabriel Horane, Remo Berardo, Horacio Elbert, José Julio Fondevila, Patricia Oviedo, las Madres de Plaza de Mayo Esther Careaga, Azucena Villaflor de De Vincenti y Mary Ponce de Bianco, y las religiosas Alice Dumon y Leonie Duquet. Los cuerpos de Villaflor de De Vincenti, Ballestrino de Careaga, Ponce de Bianco, Auad y Duquet fueron encontrados en la costa argentina ese mismo año y enterrados en tumbas nN en el cementerio de la localidad de General Lavalle. Sus restos fueron identificados en 2005 por el Equipo Argentino de Antropología Forense (EAAF). El resto de los integrantes del grupo continúan desaparecidos.

21. Memoria Abierta, Testimonio de Enrique Mario Fukman, Buenos Aires, 2001. Militante político en los 70, fue secuestrado el 18 de noviembre de 1978 y estuvo detenido en el CCD de la ESMA hasta el 18 de febrero de 1980. Su hermano, también militante, fue muerto en un enfrentamiento en 1977. 
Juicio destacando la importancia de colaborar en la construcción del andamiaje de pruebas desde la fiscalía, «Pero sabiendo que tenía una limitación, que se iba a juzgar a los represores y no se iba a juzgar ni a los ideólogos, claro, ni a los que planificaron todo eso, a los grupos económicos no se los juzgaba». Estas limitaciones eran contrapesadas con su legado potencial: «el tema de que estuvieran presos significaba entre otras cosas que era posible realmente avanzar, que era posible juzgarlos, era posible condenarlos» [Mi énfasis]. Pese a las expectativas de poder ampliar el alcance de los juicios a otros responsables de los crímenes cometidos durante la dictadura - por ejemplo, a la complicidad civil—, Fukman resalta la necesidad de construir una «memoria de la sociedad», de instaurarla como verdad colectivamente asumida, y rescata el valor del Juicio desde su presente de impunidad judicial. El Juicio a las Juntas exigió un fuerte involucramiento personal ensombrecido luego por la interrupción que significaron las mencionadas «leyes de impunidad». Desde entonces el rol de los sobrevivientes y otros testigos se ha mostrado imprescindible para el desarrollo del proceso de justicia y en particular para las políticas de memoria sobre las responsabilidades y complicidades de empresarios, integrantes de la Iglesia católica y del Poder Judicial, entre otros.

\section{Temores y certezas}

La capacidad de presión y amenaza social de las fuerzas armadas sometió a testigos, jueces y fiscales a la intimidación diaria a lo largo del Juicio. Mario César Villani ${ }^{22}$ ofrece su testimonio al Archivo Oral en 2002, cuando todavía regían los indultos y las leyes de Punto Final y de Obediencia Debida. Se refiere en extenso al temor a declarar, y en particular al temor en su familia ante el Juicio a las Juntas. Su padre, testigo de la fiscalía como él, había sido amenazado pero no quería denunciarlo ante el tribunal. Villani, que debía declarar a continuación, explica cómo puso fin al temor, precisamente, tes-

22. Memoria Abierta, Testimonio de Mario César Villani, Buenos Aires, 2002. Militante sindical y político en los años 70, fue secuestrado el 18 de noviembre de 1977 y estuvo en cautiverio en diferentes CCD hasta agosto de 1981 cuando fue liberado. 
timoniando. La carga del temor como efecto de la amenaza siempre latente para los sobrevivientes y familiares de desaparecidos se expresa como resistencia en el acto de testimoniar, en el acto de poner fin al silencio:

Entonces yo le digo: «Mirá, lo que tenemos que hacer es denunciarlo», pero él tenía mucho miedo. Entonces le dije: «Mirá, vos tenés que pasar primero. Si vos lo denunciás [la llamada] yo apoyo, pero si vos no decís nada, entonces yo me callo la boca». Y él no dijo nada, y yo doy todo el testimonio, y no digo nada de eso [la llamada] [...]. Entonces yo sé que si no doy testimonio no me lo saco más de encima, la única forma que tengo es no darle bolilla a la amenaza, porque si ellos detectan que la amenaza es efectiva, chau, a partir de ahí me van a amenazar siempre. Y no me volvieron a amenazar.

Los testimonios del juicio tuvieron un alto grado de exposición inconcebible para la época, pese a la restricción en la difusión de las filmaciones. Fueron reproducidos de manera parcial en portadas de periódicos y revistas de actualidad, en segmentos informativos especiales, programas de reflexión política en radio y televisión. Marta García de Candeloro ${ }^{23}$ recuerda de manera vívida el momento en que comprendió la exposición pública que suponía haber testimoniado en el Juicio:

Yo me acuerdo de la imagen que yo tenía del Juicio, al día siguiente, que salí y me quedé en Buenos Aires una semana y salí, y yo [en] todos los kioscos veía... En todos los diarios mi cara, porque salía el que había declarado el día anterior, entonces empecé a ver los diarios, y mi cara, y a mí me parecía mentira que se difundiera y que saliera en los diarios y todo lo que a uno le había pasado. Ese grito que uno tenía adentro, decir: «PPasó esto! Y con nosotros estaban éstos, y éstos, y éstos, que hoy no pueden hablar».

Los testigos eran recibidos en el tribunal en una sala especial junto a la Sala de Audiencias, donde permanecían por horas esperando su turno para declarar, aislados de las personas que hubieran podido acompañarlos. Ramón

23. Memoria Abierta, Testimonio de Marta Haydée García de Candeloro, Mar del Plata, 2007. Detenida junto a su esposo, el abogado Jorge Candeloro, 13 de junio de 1977 en Neuquén, ambos fueron llevados al CCD La Cueva (Mar del Plata) donde Candeloro fue asesinado el 28 de junio. García permaneció en cautiverio en distintos CCD. 
Verón ${ }^{24}$ destaca la soledad de esos momentos al trasluz de la experiencia en los juicios que se realizan desde 2006, en los cuales también testimonia:

Cuando fuimos a declarar al Juicio a las Juntas éramos cada uno solo, con su pasaje de avión o en tren y algún familiar, algún amigo, sólo uno. Y después todo muy cerca de ahí, bueno, terminó la dictadura, estábamos a dos años del gobierno de Alfonsín, pero con aquella promesa de que había desaparecidos con vida, de que... Bueno, yo había conseguido trabajo en ese momento y era todo un tema, digamos, pedir permiso para ir a declarar, no lo podía decir. Terminé mintiendo, diciendo que tenía que hacer un trámite, y después, contradictoriamente, esperaba que no leyeran los diarios porque se iban a enterar. $\mathrm{Y}$ uno... digo contradictoriamente porque uno quisiera que estas cosas... quería que se supieran y, sin embargo, había cien obreros y un grupo de empresarios y empleados administrativos que se ve que no asociaron ese nombre con mi persona, que [yo] trabajaba ahí. [...] Era aumentar más angustia a esa incertidumbre y [a la vez] tener más certezas sobre la posibilidad de que las cosas... bueno, fueron más terribles todavía. [Mi énfasis.]

La instancia de testimoniar aparece marcada por la soledad que implica no poder decir o tener que mentir en su entorno laboral y social, y se contrapone al deseo contradictorio de querer evitar el prejuicio todavía muy presente contra los relatos de los sobrevivientes, esperando no ser reconocido cuando su testimonio tome estado público (Bacci, Oberti y Skura, ob. cit.). Por otra parte, la creencia en la posibilidad de que hubiera aún detenidos con vida se derrumbaba con la sucesión de audiencias y la continuidad de testimonios que mostraban que «las cosas fueron más terribles todavía». A todo esto debían sobreponerse los testigos al entrar a la sala y hablar frente al tribunal. No sólo se iba a juzgar a los responsables del horror, también se conocería la verdad del horror a través de los testimonios, algo distinto del objetivo que se podía esperar de la Justicia.

24. Memoria Abierta, Testimonio de Ramón Verón, Rosario, 2010. Militante estudiantil y político en los años 70. Fue secuestrado junto a su compañera Hilda Cardozo, el 13 de mayo de 1978, llevados a diversos CCD en Rosario y Buenos Aires. Cardozo fue vista por última vez en el CCD La Perla (Córdoba), continúa desaparecida. Desde 1978, Verón estuvo detenido en diversas cáceles y fue liberado el 3 de diciembre de 1983. 


\section{Consideraciones finales}

Si los testimonios en el marco del Juicio a las Juntas abrieron una vía a la verdad de lo que había ocurrido durante la dictadura - que las personas podían ser desaparecidas o asesinadas por el Estado, que detenidos y desaparecidos habían sido torturados, que los lazos afectivos, sociales y políticos fueron desgarrados-, instalaron también la certeza acerca del carácter ya irreparable de esos hechos. Este saber contenido en los testimonios, en cada uno de ellos y pese a resistencias y temores, dio forma a lo más cercano a una verdad colectiva sobre aquellos hechos, legitimando el lugar de los testigos ante la sociedad al recolocar su memoria como resistencia al silencio y el olvido. Esa historia que contiene el testimonio - que no puede ser capturada por completo-, otorga como única recompensa el propio acto de narrarla y así dejar ir un poco de su carga.

La sociedad argentina de esos años recibió estos relatos quizás con el mismo asombro que Borges muestra en su Carta de Lector y, por haber abierto ese espacio de escucha, el Juicio a las Juntas Militares constituye un hito hasta hoy. Los testimonios, que desde entonces han continuado ofreciendo su trabajo memorial, con su anacronismo temido y necesario y sus tramas de tiempo y sujetos, actualizan cada vez el horizonte social de expectativas. Son muestra efectiva de que lo que pudo no tener lugar o escucha (esa sobrevivencia y su relato) es aún potencialmente enunciable, incluso si su voz llega mediada y traducida en el lenguaje procedimental de un juicio. Otros espacios testimoniales continuaron hasta hoy ese trabajo memorial escenificado en el Juicio, sus condiciones de realización y las posibilidades de reparación social que habilitan (o no) son todavía materia de discusión. Cada nueva instancia de despliegue de las memorias testimoniales arraiga ese piso de verdad y justicia que, en Argentina, no cesa de construirse desde entonces. 


\section{Referencias}

Acuña, C. y Smulovitz, C. (1995): «Militares en la transición argentina: del gobierno a la subordinación constitucional», en C. ACUÑA (et al.): Juicios, castigos y memorias: derechos humanos y justicia en la política argentina, Nueva Visión, Buenos Aires, 95-155.

Agamben, G. (2002): Lo que queda de Auschwitz. El archivo y el testigo, Homo Sacer III. Pre-textos, Valencia.

Aguilar, P. (et aL.) (2014): «¿Qué es un corpus?», Entramados y perspectivas, vol. $4 \mathrm{n}^{\circ} 4$, sept., 35-64.

Arendt, H. (1983 [1968]): «Isak Dinesen: 1885-1963», in: Men in dark times, Harcourt Brace \& Co., New York, 95-110.

— (2002 [1963]): Eichmann en Jerusalén. Un estudio sobre la banalidad del mal, Lumen, Barcelona.

Assmann, A. (2006): «History, Memory, and the Genre of Testimony», Poetics Today, vol. $27 \mathrm{n}^{\circ} 2$ (Summer), 261-273. doi 10.1215/033353722005-003.

Bacci, C.; Oberti, A. y Skura, S. (2012): «Testimonios en archivos: nuevas perspectivas». História Oral, v. 15, n. 2, jul.-dez, 33-49.

Calveiro, P. (2008): «El testigo narrador», Revista Puentes, $\mathrm{n}^{\circ}$ 24, agosto, 50-55.

Comisión Argentina para la Defensa de los Derechos Humanos (cadhu) (1979): Testimonios de los sobrevivientes del genocidio en la Argentina, CADHU, Barcelona.

Comisión Interamericana de Derechos Humanos (Cidh) (1980): Informe sobre la situación de los derechos humanos en Argentina. oEA, Nueva York.

Conadep (1985): Nunca Más. Informe de la Comisión Nacional sobre la Desaparición de Personas, еUdeBA, Buenos Aires.

Crenzel, E. (2008): La historia política del Nunca Más. La memoria de las desapariciones en Argentina, Siglo xxi, Buenos Aires.

da Silva Catela, L (2004): «Conocer el silencio. Entrevistas y estrategias de conocimiento de situaciones límites», Oficios Terrestres, Año x, $\mathrm{n}^{\circ}$ $15 / 16,42-54$.

Dollar, M. (2007): Una voz y nada más, Manantial, Buenos Aires.

FeLd, C. (2002): Del estrado a la pantalla: Las imágenes del juicio a los ex comandantes en Argentina, Siglo xxı, Madrid. 
FeLd, C. (2014): «¿Hacer visible la desaparición?: las fotografías de detenidos-desaparecidos de la esma en el testimonio de Víctor Basterra». Clepsidra, $\mathrm{N}^{\mathrm{o}}$ 1, marzo, pp. 28-51.

Felman, S. (2002): The Juridical Unconscious. Trials and Traumas in the Twentieth Century, Harvard University Press, Cambridge.

Funes, P. (2001): «Nunca Más. Memorias de las dictaduras en América Latina. Acerca de las Comisiones de Verdad en el Cono Sur», en B. Groppo y P. Flier (Orgs.): La imposibilidad del olvido. Recorridos de la memoria en Argentina, Chile y Uruguay, Al Margen, La Plata, 43-61.

González Bombal, M. I. (1995): “"Nunca más”: el juicio más allá de los estrados», en C. AcuÑa (et al.): Juicios, castigos y memorias: derechos humanos y justicia en la política argentina, Nueva Visión, Buenos Aires, 194-216.

JELIN, E. (1995): «La política de la memoria: el movimiento de derechos humanos y la construcción democrática en la Argentina», en C. Acuña (et al.): Juicios, castigos y memorias: derechos humanos y justicia en la política argentina, Nueva Visión, Buenos Aires, 103-145.

- (2006): «La narrativa personal de lo invivible», en V. Carnovale (et al.): Historia, memoria y fuentes orales, CeDInCI, Buenos Aires.

- (2007): «Víctimas, familiares o ciudadano/as: Las luchas por la legitimidad de la palabra». Cadernos Pagu, N² 29, julho-dezembro, 37-60.

- (2012): «Militantes y combatientes en la historia de las memorias: silencios, denuncias y reivindicaciones», en A. HufFsCHMID y V. DuRÁN, Topografías conflictivas: memorias, espacios y ciudades en disputa, Nueva Trilce, Buenos Aires, 43-59.

Kaufman, E. (1991): «El ritual jurídico en el juicio a los ex comandantes. La desnaturalización de lo cotidiano (Apéndice)», en R. GuBER, El salvaje metropolitano, Legasa, Buenos Aires.

Kaufman, S. (2014): «Violencia y testimonio. Notas sobre subjetividad y los relatos posibles», Clepsidra, $\mathrm{N}^{\mathrm{o}}$ 1, marzo, 100-113.

LAub, D. (1995): «Truth and Testimony: the Process and the Struggles», in C. Caruth (ed.), Trauma: Explorations in Memory, Johns Hopkins University Press, Baltimore, 61-75.

Memoria Abierta (2010): Abogados, derecho y política, Memoria Abierta, Buenos Aires. 
Messina, L. (2012): «Reflexiones en torno a la práctica testimonial sobre la experiencia concentracionaria en Argentina», Sociedad y Economía, $\mathrm{N}^{\circ} 23,37-58$.

Mignone, E. y A. Conte Mac Donell (2006 [1981]): Estrategia represiva de la dictadura militar. La doctrina del «paralelismo global», Colihue, Buenos Aires.

Nino, C. S. (1997): Juicio al mal absoluto, Emecé, Buenos Aires.

Oberti, A. (2009): «Memorias y testigos, una discusión actual», en M. DEL C. DE LA Peza (Coord.), Memoria(s) y política. Experiencia, poéticas y construcciones de nación, Prometeo-uam, Buenos Aires.

Oberti, A. (2014): «Testimonio, responsabilidad y herencia. Militancia política y afectividad en la Argentina de los años setenta», Revista MERIDIONAL, $\mathrm{N}^{\circ}$ 2, Abril, 63-88.

Peris Blanes, J. (2005): La imposible voz. Memoria y representación de los campos de concentración en Chile: la posición del testigo, Editorial Cuarto Propio, Santiago de Chile.

Pittaluga, R. (2006): «Del silencio a las nuevas preguntas. Los historiadores ante el pasado reciente», Revista PUENTES, 17 de abril, 36-40.

Pollack, M. (1986): « La gestion de l'indicible », Actes de la recherche en Sciencies Sociales, $\mathrm{n}^{\circ}$ 62/63, 30-53.

Richard, N. (2010): Crítica de la memoria (1990-2010), Universidad Diego Portales, Santiago de Chile.

Ricoeur, P. (2004): «Fase documental: La memoria archivada», en La memoria, la historia, el olvido, FCE, Buenos Aires, 189-236.

Roy, S. (2013): «On Testimony. The Pain of Speaking and the Speaking of Pain», in N. Adler \& S. LeYdeSdorfF, Tapestry of Memory: Evidence and Testimony in Life-story Narratives, Transaction Publishers, New Brunswick/NJ.

SARLo, B. (2005): Tiempo pasado. Cultura de la memoria y giro subjetivo. Una discusión, Siglo xxı, Buenos Aires.

Scotr, J. (2001): «Experiencia», La ventana, $\mathrm{n}^{\mathrm{o}}$ 13. URL: $<$ http://148.202.18.157/sitios/publicacionesite/pperiod/laventan/ Ventana13/ventana13-2.pdf $>$

Segato, R. (2010): «La lucha por el derecho a nombrar el sufrimiento en el derecho», en A. ETCHEGOYEN (comp.): Voces y silencios de la discriminación. Acceso a la Justicia. Conferencia 2009, El Mono Armado, Buenos Aires. 
SikkinK, K. (2008): «From Pariah State to Global Protagonist: Argentina and the Struggle for International Human Rights», Latin American Politics and Society, Vol. 50, No. 1 (Spring), 1-29.

Vezzetti, H. (2002): Pasado y Presente. Guerra, dictadura y sociedad en la Argentina, Siglo xxi, Buenos Aires.

Wiewiorka, A. (1998): L'ère du témoin. Plon, Paris.

Prensa

EL PAÍS, Sábado 10 de agosto de 1985. J. L. Borges, «Lunes, 22 de julio de 1985», 9. URL: <http://elpais.com/diario/1985/08/10/opinion/492472809_850215.html>

Página/12, 30 de abril de 2013. A. DANDÁN, «Otra recorrida por los recovecos de la ESMA». URL: <http://www.pagina12.com.ar/diario/ elpais/1-219018-2013-04-30.html> 